\title{
Endoscopic Evaluation of Biliary Strictures: Current and Emerging Techniques
}

\author{
Roy Huynh ${ }^{1,2}$, Corinne Owers ${ }^{1}$, Christopher Pinto ${ }^{1}$, Thuy-My Nguyen ${ }^{1}$ and Titus Kwok ${ }^{1}$ \\ ${ }^{1}$ Department of Upper Gastrointestinal Surgery, Concord Repatriation General Hospital, Sydney, NSW, ${ }^{2}$ Faculty of Medicine, University \\ of New South Wales, Sydney, NSW, Australia
}

The diagnosis of biliary strictures in clinical practice can be challenging. Discriminating between benign and malignant biliary strictures is important to prevent the morbidity and mortality associated with incorrect diagnoses. Missing a malignant biliary stricture may delay surgery, resulting in poor prognostic outcomes. Conversely, it has been demonstrated that approximately $20 \%$ of patients who undergo surgery for suspected biliary malignancies have a benign etiology on histopathology. Traditional tissue sampling using endoscopic retrograde cholangiography does not always produce a definitive diagnosis, with a considerable proportion of cases remaining as indeterminate biliary strictures. Recent advances in endoscopic techniques have the potential to improve the diagnostic and prognostic accuracy of biliary strictures. Clin Endosc 2021;54:825-832

Key Words: Bile ducts; Biliary tract neoplasm; Cholestasis; Endoscopy; Pathologic constriction

\section{INTRODUCTION}

Biliary strictures can be broadly classified into benign or malignant causes. Differentiating between the two etiologies allows timely management of malignant strictures and avoids unnecessary surgery for benign strictures. ${ }^{1}$ A common precept among surgeons is to assume that all biliary strictures are malignant until proven otherwise. ${ }^{2-4}$ This safeguards against missing a diagnosis of malignancy but has contributed to a considerable number of patients with benign biliary strictures undergoing surgery. ${ }^{5-7}$ Unfortunately, the diagnostic workup for biliary strictures is modest at best, resulting in a proportion of cases where the etiology remains unknown. ${ }^{8}$ These biliary strictures are termed "indeterminate strictures" and pose a

Received: January 12, 2021 Revised: February 11, 2021

Accepted: February 17, 2021

Correspondence: Roy Huynh

Department of Upper Gastrointestinal Surgery, Concord Repatriation General Hospital, Hospital Road, Sydney 2139, Australia

Tel: +61-2-9767-5000, Fax: +61-2-9767-7647, E-mail: roy.huynh@gmail.com ORCID: https://orcid.org/0000-0001-7125-6423

(c) This is an Open Access article distributed under the terms of the Creative Commons Attribution Non-Commercial License (http://creativecommons.org/ licenses/by-nc/3.0) which permits unrestricted non-commercial use, distribution, and reproduction in any medium, provided the original work is properly cited. therapeutic dilemma to clinicians involved in their management. ${ }^{9}$

The etiology of benign biliary strictures is diverse. Iatrogenic injury to the bile duct after cholecystectomy or liver transplantation is the most common overall cause of biliary strictures. ${ }^{10}$ Autoinflammatory causes include primary sclerosing cholangitis (PSC), ${ }^{11}$ immunoglobulin G4 (IgG4)-associated cholangitis, ${ }^{12}$ and sarcoidosis. ${ }^{13}$ Impaction of gallstones in the cystic duct or Hartmann's pouch can result in extrinsic ductal compression. ${ }^{14}$ Infective causes, such as acquired immunodeficiency syndrome cholangiopathy, are associated with multiple pathogens, ${ }^{15}$ the most common being Cryptosporidium parvum, ${ }^{16}$ although some cases may have no identifiable pathogens.

With respect to malignant biliary strictures, the two primary causes are cholangiocarcinoma and pancreatic adenocarcinoma. ${ }^{17,18}$ Malignant strictures of the proximal to middle bile duct portions are more likely to be cholangiocarcinoma than pancreatic adenocarcinoma, which tends to cause distal bile duct strictures. ${ }^{19}$ Rarer causes of malignant biliary strictures include metastatic disease, ${ }^{20}$ lymphoproliferative disease, ${ }^{21}$ gallbladder carcinoma, ${ }^{22}$ and hepatocellular carcinoma. ${ }^{23}$

The current approaches to the evaluation of biliary strictures seem to have high specificity but lack sensitivity, leading 
to diagnostic uncertainty. ${ }^{9,10}$ The fear of missing a potential malignancy has prompted many surgeons to operate in cases in which the diagnosis remains uncertain. Up to $20 \%$ of suspected biliary malignancies are revealed to be benign after surgical resection. ${ }^{5,6,24}$ Surgery is associated with appreciable morbidity and mortality rates. Hence, there is a need to develop techniques that will improve the diagnosis of biliary strictures. This article will review current and recently developed endoscopic approaches for the evaluation of biliary strictures. Conventional methods such as endoscopic retrograde cholangiopancreatography, endoscopic ultrasound, intraductal ultrasound, and cholangioscopy will be discussed along with emerging techniques such as confocal laser endomicroscopy, fluorescence in situ hybridization, and optical coherence tomography.

\section{CURRENT ENDOSCOPIC TECHNIQUES}

\section{Endoscopic retrograde cholangiopancreatography}

Endoscopic retrograde cholangiopancreatography (ERCP) remains the most widely used diagnostic approach for the evaluation of biliary strictures. Initial evaluation by ERCP allows the precise definition of the location, extent, and morphology of biliary strictures (Fig. 1)..$^{25,26}$ Malignant strictures are usually characterized as being long and irregular with

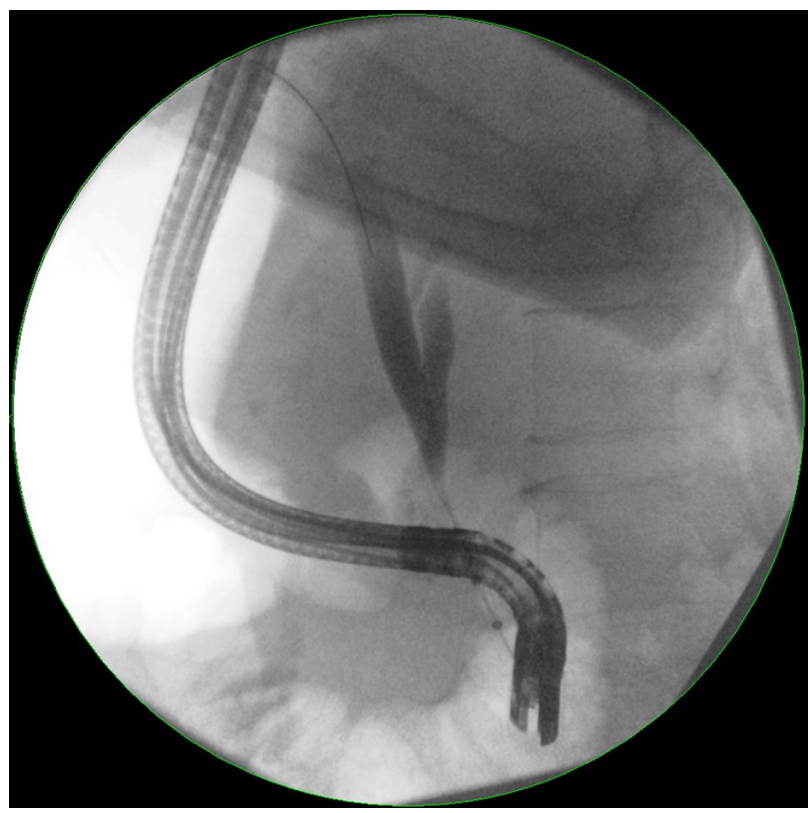

Fig. 1. Endoscopic retrograde cholangiopancreatography image showing severe stenosis in the middle to distal third portion of the common bile duct with associated upstream dilatation. evidence of shouldering. ${ }^{27,28}$ Unfortunately, the morphology of strictures is not useful in providing a specific diagnosis, and tissue sampling using either brush cytology or intraductal biopsies is required. ${ }^{29}$ Brush cytology is more commonly performed because it is easier and associated with fewer complications. ${ }^{30,31}$ Conversely, intraductal biopsies provide greater microarchitecture detail, but require sphincterotomy and can be challenging in narrow bile ducts. ${ }^{32}$ The diagnostic advantage of intraductal biopsies over cytology brushings has also not been demonstrated. A meta-analysis performed by Navaneethan et al. ${ }^{33}$ showed that the pooled sensitivity and specificity of brush cytology in the diagnosis of malignant strictures were $45 \%$ (95\% confidence interval [CI], 40-50\%) and 99\% (95\% CI, 98-100\%), respectively. For intraductal biopsies, the pooled sensitivity and specificity were comparable at $48.1 \%$ (95\% CI, 42.8-53.4\%) and 99.2\% (95\% CI, 97.6-99.8\%), respectively. Combining the two modalities increased the sensitivity marginally to $59.4 \%$ (95\% CI, 53.7-64.8\%), with a specificity of $100 \%$.

The poor sensitivity of tissue sampling through ERCP has been attributed to multiple factors, including the effects of desmoplasia in malignancy, which can reduce the yield of samples obtained with brush cytology. ${ }^{34,35}$ Furthermore, inflammation secondary to obstruction or infection can cause cellular changes such as hyperplasia or degenerative disfigurements, making it difficult to distinguish between benign and malignant lesions. ${ }^{36}$ Although the diagnostic yield of tissue sampling is reliant on the morphology of the stricture, other factors including the technical skill of the endoscopist and the interpretative ability of the pathologist remain important factors. ${ }^{37,38}$ Increasing the number of brushings has been shown to improve diagnostic accuracy; however, stricture dilation or increasing the brush length does not. ${ }^{39,40}$

\section{Endoscopic ultrasound}

Endoscopic ultrasound (EUS) can differentiate between benign and malignant strictures by allowing sonographic visualization of the biliary tract along with the surrounding viscera including the pancreas (Fig. 2). ${ }^{41}$ An echoendoscope, which comprises a transducer probe incorporated into the tip of an endoscope, is advanced into the duodenum. The transducer probe can be either radial or linear. Radial probes permit a full rotational view of the anatomy, whereas linear probes are more suitable for interventional procedures such as fine-needle aspiration (FNA). ${ }^{42}$ Assessment of the common bile duct is usually performed from the duodenal bulb, where the close proximity of the bile duct and transducer probe allows the biliary tract to be imaged along with surrounding structures such as the superior mesenteric vessels and para-aortic nodes. ${ }^{43}$ 

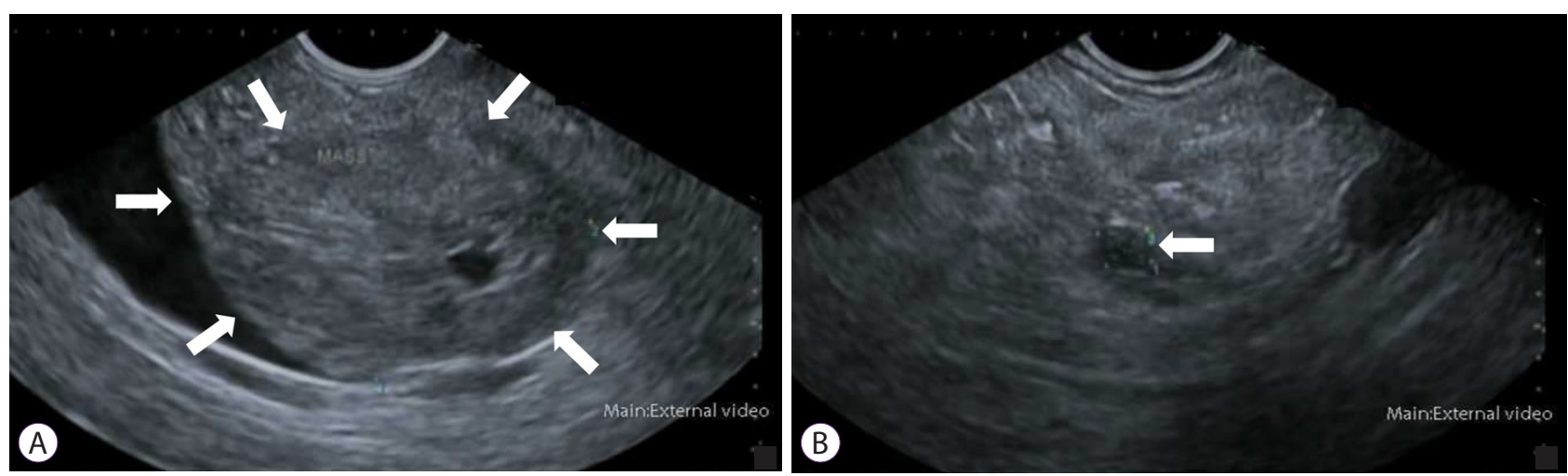

Fig. 2. Hypoechoic mass as visualized using endoscopic ultrasound. (A) Pancreatic head. (B) Pancreatic tail.

Tissue sampling through EUS-guided FNA was first performed by Fritscher-Ravens et al. ${ }^{44}$ in 10 patients with indeterminate biliary strictures. Further studies on EUS-guided FNA demonstrated improved accuracy when used in conjunction with ERCP and brush cytology. A recent meta-analysis by Sadeghi et al. ${ }^{45}$ established the pooled sensitivity and specificity of EUS-guided FNA in the diagnosis of malignant biliary strictures to be $80 \%$ (95\% CI, 74-86\%) and 97\% (95\% CI, 94-99\%), respectively. When the location of the biliary stricture was taken into consideration, EUS-guided FNA of distal strictures had a higher sensitivity (83\% [95\% CI, 68-98\%]) than that of proximal strictures (76\% [95\% CI, 66-85\%]); however, there was no difference in specificity. The practical efficacy of EUS-guided FNA depends on the site, size, and characteristics of the target lesion. ${ }^{46}$ This has prompted the development of EUS-guided fine-needle biopsy (FNB), which uses a larger needle to obtain core biopsies from the suspected lesion. EUS-guided FNB enables obtaining tissue with better integrity and microarchitecture, allowing for innovative biomarker evaluation. ${ }^{47} \mathrm{~A}$ recent randomized cross-over trial demonstrated that EUS-guided FNB had considerably higher diagnostic yield and specimen adequacy than FNA. ${ }^{48}$ The use of EUS-guided FNA and FNB for preoperative diagnosis is currently debatable, with conflicting perspectives published by different governing bodies. ${ }^{49,50}$ Given the lack of consolidated evidence, endoscopists should always consider the risk of malignant seeding when performing EUS-guided FNA or FNB, and make their decision on a case-by-case basis.

\section{Intraductal ultrasound}

Intraductal ultrasound (IDUS) has been shown to be more accurate than tissue sampling through ERCP in differentiating between benign and malignant biliary strictures. ${ }^{51-53}$ This technique makes use of a thin ultrasound probe that can be insert- ed into the biliary tract without sphincterotomy. ${ }^{54}$ Mechanical rotation of the probe permits a cross-sectional view of the bile duct. Features suggestive of malignancy include the presence of a sessile tumor, an interrupted wall structure, and a tumor size $>10 \mathrm{~mm}$. Tamada et al..$^{55}$ demonstrated that if IDUS showed at least two of these features, a malignancy should be considered even if the histologic findings are negative. The diagnostic utility of IDUS was assessed by Heinzow et al. ${ }^{56}$ in 234 patients with indeterminate biliary strictures. IDUS was diagnostically superior to endoscopic transpapillary biopsies, EUS, and computed tomography in detecting malignant biliary strictures. The sensitivity and specificity of IDUS in this study were determined to be $93 \%$ (95\% CI, 88-97\%) and $89 \%$ (95\% CI, 83-95\%), respectively.

A major limitation of earlier IDUS was the inability to obtain biopsies for pathologic diagnosis. More recently, transpapillary biopsies have been performed under IDUS guidance. Kim et al. ${ }^{57}$ performed a prospective comparative study that showed that IDUS-guided transpapillary biopsy has a higher diagnostic accuracy than fluoroscopic-guided transpapillary biopsy for the diagnosis of malignant biliary strictures ( $90.8 \%$ vs. $76.9 \%, p=0.027$ ). The role of EUS can extend beyond the diagnosis and toward the staging of malignant strictures. IDUS has been shown to be more accurate than EUS in the T-staging of tumors. ${ }^{58,59}$ However, the high frequencies used in IDUS preclude accurate nodal staging owing to poor tissue penetration. ${ }^{60}$ IDUS may play a role in evaluating indeterminate biliary strictures; however, it is currently limited by the lack of technical expertise required to perform this procedure. Furthermore, previously placed stents can produce acoustic interference, reducing the diagnostic yield of IDUS. ${ }^{61}$

\section{Cholangioscopy}

Direct visualization of the bile duct can be achieved using 
per-oral cholangioscopy. This technique initially lost popularity owing to its requirement for two endoscopists to operate the mother-baby endoscope. Additionally, the procedure was limited by poor maneuverability, small instrument channels, and inadequate tip deflection. ${ }^{62}$ The development of single-operator cholangioscopy has recently led to a resurgence of interest in the use of this technique. Cholangioscopic inspection of the epithelium may provide macroscopic clues pertaining to malignancy. Any intraductal masses, nodules, or ulcerations should prompt direct biopsies from the region. ${ }^{16}$ The presence of a "tumor vessel," an irregular, dilated, and tortuous vessel, is considered a reliable feature of biliary malignancy. ${ }^{63,64} \mathrm{~A}$ meta-analysis performed by Sun et al. ${ }^{65}$ demonstrated that visual inspection alone using cholangioscopy is useful for detecting biliary malignancy, with pooled sensitivity and specificity of 90\% (95\% CI, 73-97\%) and 87\% (95\% CI, 76-94\%), respectively. However, confirmation using cholangioscopic-directed biopsies is still needed, which has an overall sensitivity and specificity of 69\% (95\% CI, 57-79\%) and 98\% (95\% CI, 92-99\%), respectively. Despite its diagnostic utility, the uptake of cholangioscopy has been relatively limited in many endoscopy centers. Many endoscopists perceive the procedure to be technically difficult, as it requires mastery in ERCP while concurrently operating the cholangioscope through the working channel. Nonetheless, studies have demonstrated a relatively quick learning curve with reportedly only 10 procedures needed to gain proficiency. ${ }^{66,67}$ Cholangioscopy has been assessed by many studies to be a safe procedure even in elderly and comorbid patients. ${ }^{68,69}$ Further research and development in cholangioscopy may increase the uptake of this technique in the future.

\section{EMERGING ENDOSCOPIC TECHNIQUES}

\section{Confocal laser endomicroscopy}

Confocal laser endomicroscopy (CLE) is a promising technique that can provide real-time, in vivo histologic imaging of the bile duct during ERCP. ${ }^{70-72}$ The principle of CLE is based on the reflection of focused light through a confocal aperture to provide high-resolution histologic images (Fig. 3). This technique is performed using a catheter probe that is inserted through the working channel of an endoscope (probe-based CLE) or FNA equipment (needle-based CLE) ${ }^{73}$ The probe

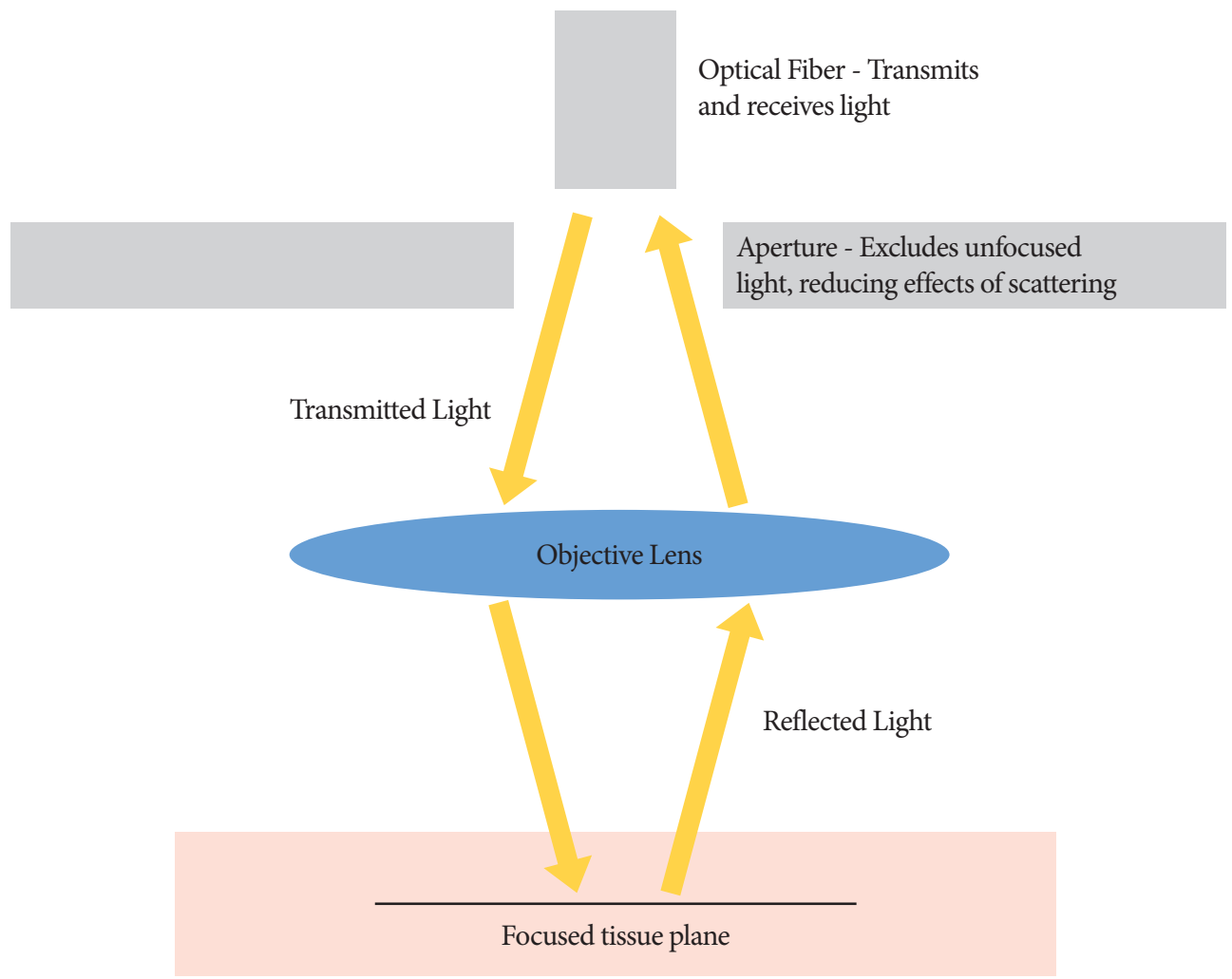

Fig. 3. In confocal laser endomicroscopy, a low-power laser is directed onto a selected horizontal tissue plane and reflected to produce histological images. Out of focus reflected light are filtered out by the aperture, thus producing high-resolution images. 
is advanced into the biliary system and the patient is injected with a contrast agent such as fluorescein, which extravasates into the biliary vasculature, highlighting the epithelial and subepithelial structures. ${ }^{72-74}$ The diagnosis of a malignancy using CLE is based on the Miami classification criteria. ${ }^{74}$ The malignant features according to these criteria include thick dark bands $>40 \mu \mathrm{m}$, thick white bands $>20 \mu \mathrm{m}$, epithelial structures, and dark clumps. CLE and the Miami classification have demonstrated better sensitivity but poorer specificity than traditional histology in the evaluation of biliary strictures. The low specificity has been attributed to changes induced by chronic inflammation or procedures performed during ERCP, such as cytology brushing. ${ }^{75}$ To address this issue, the Paris classification was developed by Caillol et al. ${ }^{76}$ to differentiate between benign inflammatory strictures and malignant strictures. The presence of vascular congestion, increased interglandular space, thickened reticular structures, and a granular pattern with scales are all features indicative of inflammatory biliary strictures.

Results from early studies exploring the use of CLE in the diagnosis of biliary strictures suggested an optimistic future. In a recent meta-analysis analyzing 12 studies involving 591 patients, Gao et al. ${ }^{77}$ determined that the pooled sensitivity and specificity of CLE in discriminating between benign and malignant biliary strictures were 87\% (95\% CI, 83-91\%) and 76\% (95\% CI, 70-81\%), respectively. When used in combination with tissue sampling, the sensitivity and specificity increased to $93 \%$ (95\% CI, $88-96 \%$ ) and $82 \%$ (95\% CI, 74-89\%), respectively. However, the uptake of CLE has been slow. This may be because the procedure is technically difficult, as it requires probe stability to ensure high-quality images. Furthermore, the interobserver agreement between experienced endoscopists is poor, raising doubts about its diagnostic reliability. ${ }^{78}$ However, these shortcomings can be overcome with standardized training. ${ }^{79}$ Currently, CLE is practiced at only a few specialized centers and requires further validation to consolidate its place in clinical practice.

\section{Fluorescence in situ hybridization}

Fluorescence in situ hybridization (FISH) has been used for the detection of other malignancies, such as urothelial carcinoma, before its application in the evaluation of biliary strictures. ${ }^{80}$ This technique makes use of fluorescently labeled DNA probes to detect aneuploidy associated with malignant biliary strictures. More specifically, polysomy of chromosomes 3,7 , and 17 centromeric regions or of the $1 \mathrm{q} 21,7 \mathrm{p} 12$, or 8 q24 chromosomal region has been considered useful in the detection of malignant biliary strictures. ${ }^{81-83}$ Multiple studies have demonstrated that FISH can increase the sensitivity of cytology brushing while preserving specificity. ${ }^{81,83-86}$ The most recent study is that by Liew et al., ${ }^{87}$ who performed a retrospective analysis of 30 consecutive patients who underwent both routine cytology and FISH performed at a tertiary care center. When used independently, routine brush cytology had a higher sensitivity ( $53.8 \%$ vs. $30.8 \%$ ) but a lower specificity (82.4\% vs. $100 \%$ ) than FISH. However, when the FISH results were interpreted in cases of negative or atypical cytology findings, the sensitivity of brush cytology improved from $53.8 \%$ to $69.2 \%$ without compromising specificity.

A well-studied aspect of FISH is the detection of cholangiocarcinoma in PSC. PSC can be difficult to distinguish from cholangiocarcinoma because these two conditions can have similar imaging features. ${ }^{88}$ In addition, some patients with PSC may progress to develop cholangiocarcinoma. ${ }^{89}$ In such cases, FISH can be used to determine whether cholangiocarcinoma progression has occurred. A meta-analysis of eight studies involving 828 patients demonstrated that the pooled sensitivity and specificity for the diagnosis of cholangiocarcinoma in PSC were 68\% (95\% CI, 61-74\%) and 70\% (95\% CI, 66-73\%), respectively. ${ }^{90}$ These results showed that FISH increases the sensitivity of tissue sampling only slightly in PSC. However, the high cost of FISH has prompted some endoscopists to be selective in using this tool for detecting malignancies. ${ }^{91}$ FISH is not recommended as a screening tool for all patients with PSC but should be considered if the suspicion of malignancy remains high after an inconclusive brush cytology.

\section{Optical coherence tomography}

Optical coherence tomography (OCT) enables high-resolution cross-sectional imaging of the biliary tract. ${ }^{92}$ The principle of OCT is similar to that of B-mode ultrasound, except that it uses infrared light instead of high-frequency sound. By measuring the intensity and time delay of backscattered infrared light, cross-sectional images of the biliary tract can be obtained in real time. ${ }^{93}$ Neoplastic and normal tissues display different light-backscattering patterns, permitting OCT to differentiate between benign and malignant strictures. ${ }^{94}$ The spatial resolution of OCT is almost equivalent to that of histology, allowing clear visualization of the epithelium, fibroconnective submucosa, and acinar tissue as a series of hyperreflective and hyporeflective layers. ${ }^{93,95}$ Following ex vivo studies demonstrating that OCT could produce images of the bile duct to a depth of 1 $\mathrm{mm}$, multiple subsequent in vivo studies showed characteristic changes that occur in benign and malignant strictures. ${ }^{96-98} \mathrm{Ar}-$ vanitakis et al. ${ }^{99}$ evaluated the use of OCT in 37 patients with biliary strictures, and demonstrated that the sensitivity and specificity in detecting malignancy can reach $79 \%$ and $100 \%$, respectively, depending on the criteria used. 
Most of the studies on OCT have been based on first-generation devices that are no longer in production. The second-generation OCT system offers higher imaging speed without compromising image quality or spatial resolution. ${ }^{100}$ Images retrieved using the newer-generation OCT system were still able to outline characteristic features of benign and malignant strictures, as evaluated by Tyberg et al. ${ }^{101}$ Both the first- and second-generation OCT devices were miniaturized enough that they could be inserted into the working channel of an endoscope. ${ }^{102}$ Once positioned in the stricture, imaging of the stricture takes approximately $90 \mathrm{~s}$ and in vivo interpretation can be accomplished. ${ }^{101}$ The relative efficiency of this technique in detecting features suggestive of malignancy has increased its approval among endoscopists. However, further studies with large numbers of prospective patients are needed to determine how OCT can be employed in future diagnostic algorithms for the evaluation of biliary strictures.

\section{CONCLUSIONS}

The evaluation of biliary strictures remains challenging despite recent advances in endoscopic techniques. The decision to favor one endoscopic approach over another should be individualized; however, the lack of large-scale prospective studies on newer modalities makes this decision difficult. The diagnosis of biliary strictures can be aided by developments in cytopathologic staining and imaging practices. Thus, a multidisciplinary approach involving endoscopists, surgeons, pathologists, and radiologists is necessary to provide a holistic direction for diagnosis. Future advances in endoscopy will undoubtedly improve the detection of malignant biliary strictures. In the meantime, clinicians should tailor their decision making to the clinical condition of individual patients when diagnosing biliary strictures.

\section{Conflicts of Interest}

The authors have no potential conflicts of interest.

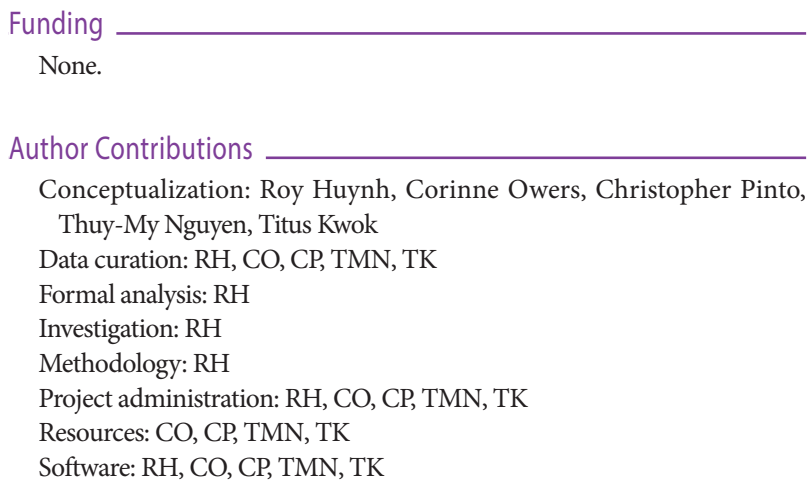

Supervision: TK

Validation: RH, CO, CP, TMN, TK

Visualization: RH, CO, CP, TMN, TK

Writing-original draft: $\mathrm{RH}$

Writing-review\&editing: RH, CO, CP, TMN, TK

ORCID
Roy Huynh:

Corinne Owers:

Christopher Pinto:

Thuy-My Nguyen:

Titus Kwok:

\author{
https://orcid.org/0000-0001-7125-6423 \\ https://orcid.org/0000-0003-0090-2904 \\ https://orcid.org/0000-0002-7157-3303 \\ https://orcid.org/0000-0002-1385-7260 \\ https://orcid.org/0000-0001-9660-1828
}

\section{REFERENCES}

1. Dawwas MF, Oppong KW, Webster GJ. Endoscopic assessment and management of biliary strictures. Frontline Gastroenterol 2016;7:170175.

2. Jha R, Al-Kawas FH. How good is IDUS in patients with isolated biliary strictures? A J Gastroenterol 2004;99:1690-1691.

3. Larghi A, Waxman I. Differentiating benign from malignant idiopathic biliary strictures: are we there yet? Gastrointest Endosc 2007;66:97-99.

4. Longmire WP, Macarthur MS, Bastounis EA, Hiatt J. Carcinoma of the extrahepatic biliary tract. Ann Surg 1973;178:333-345.

5. Gerhards MF, Vos P, Van Gulik TM, Rauws EA, Bosma A, Gouma DJ. Incidence of benign lesions in patients resected for suspicious hilar obstruction. British J Surg 2001;88:48-51.

6. Clayton RaE, Clarke DL, Currie EJ, Madhavan KK, Parks RW, Garden OJ. Incidence of benign pathology in patients undergoing hepatic resection for suspected malignancy. Surgeon 2003;1:32-38.

7. Wakai T, Shirai Y, Sakata J, et al. Clinicopathological features of benign biliary strictures masquerading as biliary malignancy. Am Surg 2012;78:1388-1391.

8. Hall JG, Pappas TN. Current management of biliary strictures. J Gastrointest Surg 2004;8:1098-1110.

9. Bowlus CL, Olson KA, Gershwin ME. Evaluation of indeterminate biliary strictures. Nat Rev Gastroenterol Hepatol 2016;13:28-37.

10. Martin RF, Rossi RL. Bile duct injuries: spectrum, mechanisms of injury, and their prevention. Surg Clin North Am 1994;74:781-803.

11. Kaya M, Petersen BT, Angulo P, et al. Balloon dilation compared to stenting of dominant strictures in primary sclerosing cholangitis. Am J Gastroenterol 2001;96:1059-1066.

12. Ohara $\mathrm{H}$, Okazaki $\mathrm{K}$, Tsubouchi $\mathrm{H}$, et al. Clinical diagnostic criteria of IgG4-related sclerosing cholangitis 2012. J Hepatobiliary Pancreat Sci 2012;19:536-542.

13. Alam I, Levenson SD, Ferrell LD, Bass NM. Diffuse intrahepatic biliary strictures in sarcoidosis resembling sclerosing cholangitis (case report and review of the literature). Dig Dis Sci 1997;42:1295-1301.

14. Wong CS, Al-Ajami AK, Crotty JM, Naqvi SA. Benign biliary stricture and its rare association-Mirizzi syndrome: a case series and literature review. Int J Case Rep Imag 2012;3:1-7.

15. Liberman E, Yen TS. Foamy macrophages in acquired immunodeficiency syndrome cholangiopathy with Encephalitozoon intestinalis. Arch Pathol Lab Med 1997;121:985-988.

16. Chen XM, LaRusso NF. Cryptosporidiosis and the pathogenesis of AIDS-cholangiopathy. Semin Liver Dis 2002;22:277-290.

17. Singh A, Gelrud A, Agarwal B. Biliary strictures: diagnostic considerations and approach. Gastroenterol Rep 2015;3:22-31.

18. Xie C, Aloreidi K, Patel B, et al. Indeterminate biliary strictures: a simplified approach. Expert Rev Gastroenterol Hepatol 2018;12:189-199.

19. Salgado SM, Gaidhane M, Kahaleh M. Endoscopic palliation of malignant biliary strictures. World J Gastrointest Oncol 2016;8:240-247. 
20. Stewart CJ, Mills PR, Carter R, et al. Brush cytology in the assessment of pancreatico-biliary strictures: a review of 406 cases. J Clin Pathol 2001;54:449-455.

21. Ödemiş B, Parlak E, Başar Ö, Yüksel O, Şahin B. Biliary tract obstruction secondary to malignant lymphoma: experience at a referral center. Dig Dis Sci 2007;52:2323-2332.

22. Kurzawinski TR, Deery A, Dooley JS, Dick R, Hobbs KE, Davidson BR. A prospective study of biliary cytology in 100 patients with bile duct strictures. Hepatology 1993;18:1399-1403.

23. Seo DW, Lee SK, Yoo KS, et al. Cholangioscopic findings in bile duct tumors. Gastrointest Endosc 2000;52:630-634.

24. Uhlmann D, Wiedmann M, Schmidt F, et al. Management and outcome in patients with Klatskin-mimicking lesions of the biliary tree. J Gastrointest Surg 2006;10:1144-1150.

25. Paranandi B, Oppong KW. Biliary strictures: endoscopic assessment and management. Frontline Gastroenterol 2017 Apr 1;8:133-137.

26. Adler DG, Baron TH, Davila RE, et al. ASGE guideline: the role of $\mathrm{ERCP}$ in diseases of the biliary tract and the pancreas. Gastrointest Endosc 2005;62:1-8.

27. Moon YM, Kim WH, Shin ST, et al. A study of 122 cases of pancreatic cancer diagnosed by endoscopic retrograde cholangiopancreatography (ERCP). Korean J Intern Med 1986;1:131-139.

28. Park MS, Kim TK, Kim KW, et al. Differentiation of extrahepatic bile duct cholangiocarcinoma from benign stricture: findings at MRCP versus ERCP. Radiology 2004;233:234-240.

29. Kalaitzakis E, Levy M, Kamisawa T, et al. Endoscopic retrograde cholangiography does not reliably distinguish IgG4-associated cholangitis from primary sclerosing cholangitis or cholangiocarcinoma. Clin Gastroenterol Hepatol 2011;9:800-803.

30. Burnett AS, Calvert TJ, Chokshi RJ. Sensitivity of endoscopic retrograde cholangiopancreatography standard cytology: $10-\mathrm{y}$ review of the literature. J Surg Res 2013;184:304-311.

31. Trikudanathan G, Navaneethan U, Njei B, Vargo JJ, Parsi MA. Diagnostic yield of bile duct brushings for cholangiocarcinoma in primary sclerosing cholangitis: a systematic review and meta-analysis. Gastrointest Endosc 2014;79:783-789.

32. Kitajima $Y$, Ohara $\mathrm{H}$, Nakazawa T, et al. Usefulness of transpapillary bile duct brushing cytology and forceps biopsy for improved diagnosis in patients with biliary strictures. J Gastroenterol Hepatol 2007;22:16151620.

33. Navaneethan U, Njei B, Lourdusamy V, Konjeti R, Vargo JJ, Parsi MA. Comparative effectiveness of biliary brush cytology and intraductal biopsy for detection of malignant biliary strictures: a systematic review and meta-analysis. Gastrointest Endosc 2015;81:168-176.

34. Athanassiadou P, Grapsa D. Value of endoscopic retrograde cholangiopancreatography-guided brushings in preoperative assessment of pancreaticobiliary strictures: what's new? Acta Cytol 2008;52:24-34.

35. Kurzawinski T, Deery A, Davidson BR. Diagnostic value of cytology for biliary stricture. Br J Surg 1993;80:414-421.

36. Rupp M, Hawthorne CM, Ehya H. Brushing cytology in biliary tract obstruction. Acta Cytol 1990;34:221-226.

37. Pugliese V, Conio M, Nicolò G, Saccomanno S, Gatteschi B. Endoscopic retrograde forceps biopsy and brush cytology of biliary strictures: a prospective study. Gastrointest Endosc 1995;42:520-526.

38. Okonkwo AM, De Frias DVS, Gunn R, et al. Reclassification of "atypical" diagnoses in endoscopic retrograde cholangiopancreaticography-guided biliary brushings. Acta Cytol 2003;47:435-442.

39. De Bellis M, Fogel EL, Sherman S, et al. Influence of stricture dilation and repeat brushing on the cancer detection rate of brush cytology in the evaluation of malignant biliary obstruction. Gastrointest Endosc 2003;58:176-182.

40. Fogel EL, De Bellis M, McHenry L, et al. Effectiveness of a new long cytology brush in the evaluation of malignant biliary obstruction: a prospective study. Gastrointest Endosc 2006;63:71-77.
41. Mishra G, Conway JD. Endoscopic ultrasound in the evaluation of radiologic abnormalities of the liver and biliary tree. Curr Gastroenterol Rep 2009;11:150-154.

42. Chung A, Kwan V. Endoscopic ultrasound: an overview of its role in current clinical practice. Australas J Ultrasound Med 2009;12:21-29.

43. Conway JD, Mishra G. The role of endoscopic ultrasound in biliary strictures. Curr Gastroenterol Rep 2008;10:157-162.

44. Fritscher-Ravens A, Broering DC, Sriram PV, et al. EUS-guided fine-needle aspiration cytodiagnosis of hilar cholangiocarcinoma: a case series. Gastrointest Endosc 2000;52:534-540.

45. Sadeghi A, Mohamadnejad M, Islami F, et al. Diagnostic yield of EUS-guided FNA for malignant biliary stricture: a systematic review and meta-analysis. Gastrointest Endosc 2016;83:290-298.

46. Ge N, Zhang S, Jin Z, et al. Clinical use of endoscopic ultrasound-guided fine-needle aspiration: guidelines and recommendations from Chinese Society of Digestive Endoscopy. Endosc Ultrasound 2017;6:75-82.

47. Levy MJ, Wiersema MJ. EUS-guided trucut biopsy. Gastrointest Endosc 2005;62:417-426.

48. Rodrigues-Pinto E, Grimm IS, Baron TH. Endoscopic ultrasound fine-needle aspiration vs. fine-needle biopsy: tissue is always the issue. Endosc Int Open 2016;4:E506-E507.

49. Aadam AA, Wani S, Amick A, et al. A randomized controlled cross-over trial and cost analysis comparing endoscopic ultrasound fine needle aspiration and fine needle biopsy. Endosc Int Open 2016;4:E497-E505.

50. Cosgrove ND, Yan L, Siddiqui A. Preoperative endoscopic ultrasound-guided fine needle aspiration for diagnosis of pancreatic cancer in potentially resectable patients: Is this safe? Endosc Ultrasound 2015;4:81-84.

51. Vazquez-Sequeiros E, Baron TH, Clain JE, et al. Evaluation of indeterminate bile duct strictures by intraductal US. Gastrointest Endosc 2002;56:372-379.

52. Domagk D, Poremba C, Dietl KH, et al. Endoscopic transpapillary biopsies and intraductal ultrasonography in the diagnostics of bile duct strictures: a prospective study. Gut 2002;51:240-244.

53. Farrell RJ, Agarwal B, Brandwein SL, Underhill J, Chuttani R, Pleskow DK. Intraductal US is a useful adjunct to ERCP for distinguishing malignant from benign biliary strictures. Gastrointest Endosc 2002;56:681687.

54. Menzel J, Domschke W. Intraductal ultrasonography (IDUS) of the pancreato-biliary duct system: personal experience and review of literature. Eir J Ultrasound 1999;10:105-115.

55. Tamada K, Tomiyama T, Wada S, et al. Endoscopic transpapillary bile duct biopsy with the combination of intraductal ultrasonography in the diagnosis of biliary strictures. Gut 2002;50:326-331.

56. Heinzow HS, Kammerer S, Rammes C, Wessling J, Domagk D, Meister T. Comparative analysis of ERCP, IDUS, EUS and CT in predicting malignant bile duct strictures. World J Gastroenterol 2014;20:10495-10503.

57. Kim HS, Moon JH, Lee YN, et al. Prospective comparison of intraductal ultrasonography-guided transpapillary biopsy and conventional biopsy on fluoroscopy in suspected malignant biliary strictures. Gut Liver 2018;12:463-470.

58. Menzel J, Hoepffner N, Sulkowski U, et al. Polypoid tumors of the major duodenal papilla: preoperative staging with intraductal US, EUS, and CT-a prospective, histopathologically controlled study. Gastrointest Endosc 1999;49:349-357.

59. Menzel J, Poremba C, Dietl KH, Domschke W. Preoperative diagnosis of bile duct strictures--comparison of intraductal ultrasonography with conventional endosonography. Scand J Gastroenterol 2000;35:77-82.

60. Rizvi S, Eaton J, Yang JD, Chandrasekhara V, Gores GJ. Emerging technologies for the diagnosis of perihilar cholangiocarcinoma. Semin Liver Dis 2018;38:160-169.

61. Lee JH, Salem R, Aslanian H, Chacho M, Topazian M. Endoscopic ultrasound and fine-needle aspiration of unexplained bile duct strictures. Am J Gastroenterol 2004;99:1069-1073. 
62. Monga A, Ramchandani M, Reddy DN. Per-oral cholangioscopy. J Interv Gastroenterol 2011;1:70-77.

63. Kim HJ, Kim MH, Lee SK, Yoo KS, Seo DW, Min YI. Tumor vessel: a valuable cholangioscopic clue of malignant biliary stricture. Gastrointest Endosc 2000;52:635-638

64. Nimura Y, Kamiya J, Hayakawa N, Shionoya S. Cholangioscopic differentiation of biliary strictures and polyps. Endoscopy 1989;21:351-356.

65. Sun X, Zhou Z, Tian J, et al. Is single-operator peroral cholangioscopy a useful tool for the diagnosis of indeterminate biliary lesion? A systematic review and meta-analysis. Gastrointest Endosc 2015;82:79-87.

66. Shah RJ, Neuhaus H, Parsi M, Reddy DN, Pleskow DK. Randomized study of digital single-operator cholangioscope compared to fiberoptic single-operator cholangioscope in a novel cholangioscopy bench model. Endosc Int Open 2018;6:E851-E858.

67. Draganov P. The SpyGlass ${ }^{\circledR}$ direct visualization system for cholangioscopy. Gastroenterol Hepatol 2008;4:469-470.

68. Bernica J, Elhanafi S, Kalakota N, et al. Cholangioscopy is safe and feasible in elderly patients. Clin Gastroenterol Hepatol 2018;16:1293-1299.

69. Wong JC, Tang RS, Teoh AY, Sung JJ, Lau JY. Efficacy and safety of novel digital single-operator peroral cholangioscopy-guided laser lithotripsy for complicated biliary stones. Endosc Int Open 2017;5:E54-E58.

70. Shieh FK, Drumm H, Nathanson MH, Jamidar PA. High-definition confocal endomicroscopy of the common bile duct. J Clin Gastroenterol 2012;46:401-406.

71. Polglase AL, McLaren WJ, Delaney PM. Pentax confocal endomicroscope: a novel imaging device for in vivo histology of the upper and lower gastrointestinal tract. Expert Rev Med Devices 2006;3:549-556.

72. Meining A, Saur D, Bajbouj M, et al. In vivo histopathology for detection of gastrointestinal neoplasia with a portable, confocal miniprobe: an examiner blinded analysis. Clin Gastroenterol Hepatol 2007;5:12611267.

73. De Palma GD. Confocal laser endomicroscopy in the "in vivo" histological diagnosis of the gastrointestinal tract. World J Gastroenterol 2009;15:5770-5775.

74. Meining A, Shah RJ, Slivka A, et al. Classification of probe-based confocal laser endomicroscopy findings in pancreaticobiliary strictures. Endoscopy 2012;44:251-257.

75. Meining A, Chen YK, Pleskow D, et al. Direct visualization of indeterminate pancreaticobiliary strictures with probe-based confocal laser endomicroscopy: a multicenter experience. Gastrointest Endosc 2011;74:961-968.

76. Caillol F, Filoche B, Gaidhane M, Kahaleh M. Refined probe-based confocal laser endomicroscopy classification for biliary strictures: the Paris classification. Dig Dis Sci 2013;58:1784-1789.

77. Gao YD, Qu YW, Liu HF. Comparison of diagnostic efficacy between CLE, tissue sampling, and CLE combined with tissue sampling for undetermined pancreaticobiliary strictures: a meta-analysis. Scand J Gastroenterol 2018;53:482-489.

78. Talreja JP, Sethi A, Jamidar PA, et al. Interpretation of probe-based confocal laser endomicroscopy of indeterminate biliary strictures: is there any interobserver agreement? Dig Dis Sci 2012;57:3299-3302.

79. Talreja JP, Turner BG, Gress FG, et al. Pre-and post-training session evaluation for interobserver agreement and diagnostic accuracy of probebased confocal laser endomicroscopy for biliary strictures. Dig Endosc 2014;26:577-580.

80. Hajdinjak T. UroVysion FISH test for detecting urothelial cancers: meta-analysis of diagnostic accuracy and comparison with urinary cytology testing. Urol Oncol 2008;26:646-651.

81. Moreno Luna LE, Kipp B, Halling KC, et al. Advanced cytologic techniques for the detection of malignant pancreatobiliary strictures. Gastroenterology 2006;131:1064-1072.

82. Fritcher EG, Kipp BR, Halling KC, et al. A multivariable model using advanced cytologic methods for the evaluation of indeterminate pancreatobiliary strictures. Gastroenterology 2009;136:2180-2186.

83. Kipp BR, Stadheim LM, Halling SA, et al. A comparison of routine cytology and fluorescence in situ hybridization for the detection of malignant bile duct strictures. Am J Gastroenterol 2004;99:1675-1681.

84. Smoczynski M, Jablonska A, Matyskiel A, et al. Routine brush cytology and fluorescence in situ hybridization for assessment of pancreatobiliary strictures. Gastrointest Endosc 2012;75:65-73.

85. Chaiteerakij R, Barr Fritcher EG, Angsuwatcharakon P, et al. Fluorescence in situ hybridization compared with conventional cytology for the diagnosis of malignant biliary tract strictures in Asian patients. Gastrointest Endosc 2016;83:1228-1235.

86. Wu X, Zeng X, Yang A, et al. Fluorescence in situ hybridization with the urovysion kit for the detection of biliary cancer in Chinese patients. Clin Lab 2017;63:407-413.

87. Liew ZH, Loh TJ, Lim TKH, et al. Role of fluorescence in situ hybridization in diagnosing cholangiocarcinoma in indeterminate biliary strictures. J Gastroenterol Hepatol 2018;33:315-319.

88. Menias CO, Surabhi VR, Prasad SR, Wang HL, Narra VR, Chintapalli $\mathrm{KN}$. Mimics of cholangiocarcinoma: spectrum of disease. Radiographics 2008;28:1115-1129.

89. Takakura WR, Tabibian JH, Bowlus CL. The evolution of natural history of primary sclerosing cholangitis. Curr Opin Gastroenterol 2017;33:7177.

90. Navaneethan U, Njei B, Venkatesh PG, Vargo JJ, Parsi MA. Fluorescence in situ hybridization for diagnosis of cholangiocarcinoma in primary sclerosing cholangitis: a systematic review and meta-analysis. Gastrointest Endosc 2014;79:943-950.

91. Bangarulingam SY, Bjornsson E, Enders F, et al. Long-term outcomes of positive fluorescence in situ hybridization tests in primary sclerosing cholangitis. Hepatology 2010;51:174-180.

92. Testoni PA, Mangiavillano B, Mariani A. Optical coherence tomography for investigation of the pancreatico-biliary system: still experimental? JOP 2007;8:156-165

93. Testoni PA, Mangiavillano B. Optical coherence tomography for bile and pancreatic duct imaging. Gastrointest Endosc Clin N Am 2009;19:637653

94. Testoni PA, Mangiavillano B. Optical coherence tomography in detection of dysplasia and cancer of the gastrointestinal tract and bilio-pancreatic ductal system. World J Gastroenterol 2008;14:6444-6452.

95. Singh P, Chak A, Willis JE, Rollins A, Sivak Jr MV. In vivo optical coherence tomography imaging of the pancreatic and biliary ductal system. Gastrointest Endosc 2005;62:970-974.

96. Testoni PA, Mariani A, Mangiavillano B, et al. Main pancreatic duct, common bile duct and sphincter of Oddi structure visualized by optical coherence tomography: An ex vivo study compared with histology. Dig Liver Dis 2006;38:409-414

97. Seitz U, Freund J, Jaeckle S, et al. First in vivo optical coherence tomography in the human bile duct. Endoscopy 2001;33:1018-1021.

98. Poneros JM, Tearney GJ, Shiskov M, et al. Optical coherence tomography of the biliary tree during ERCP. Gastrointest Endosc 2002;55:84-88.

99. Arvanitakis M, Hookey L, Tessier G, et al. Intraductal optical coherence tomography during endoscopic retrograde cholangiopancreatography for investigation of biliary strictures. Endoscopy 2009;41:696-701.

100.De Boer JF, Leitgeb R, Wojtkowski M. Twenty-five years of optical coherence tomography: the paradigm shift in sensitivity and speed provided by Fourier domain OCT. Biomed Opt Express 2017;8:3248-3280.

101.Tyberg A, Xu MM, Gaidhane M, Kahaleh M. Second generation optical coherence tomography: preliminary experience in pancreatic and biliary strictures. Dig Liver Dis 2018;50:1214-1217.

102. Yoon WJ, Brugge WR. Endoscopic evaluation of bile duct strictures. Gastrointest Endosc Clin N Am 2013;23:277-293. 